\title{
Revista
}

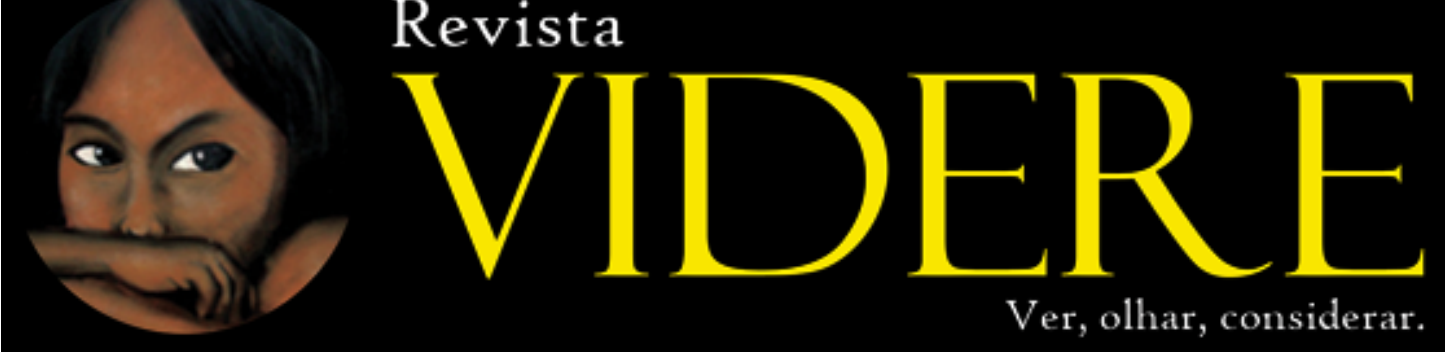

\section{Paradoxos do refúgio e reassentamento como solução duradoura}

\section{Asylum paradoxes and resettlement as a durable solution}

\author{
Bárbara Bruna de Oliveira Simões \\ Doutoranda em Ciências Sociais (PUC-RS) \\ Pontifícia Universidade Católica do Rio Grande do Sul (PUC-RS) \\ Porto Alegre, Rio Grande do Sul, Brasil \\ E-mail: barbarabsimoes@gmail.com
}

Resumo: Trata-se de pesquisa sobre o instituto do refúgio e as soluções duradouras, em especial, o reassentamento de refugiados. O refúgio foi institucionalizado na década de 50 , mas, atualmente, tem-se novos fatores que geram fluxos de pessoas para fora de suas nações de origem. Atentando para a situação não pontual do refúgio, criaram-se as soluções duradouras, a saber, repatriação voluntária, integração local e reassentamento. As soluções são, justamente, uma maneira de dar continuidade à vida do refugiado, independente do local onde ele esteja. O reassentamento é a solução que lida com os refugiados mais vulneráveis, pois fogem de seu Estado e, também, do primeiro Estado de acolhida. Visando analisar a situação não pontual do refúgio e o papel do reassentamento, utiliza-se o método dedutivo, por meio de material bibliográfico e documental. O reassentamento é uma solução importante para refugiados que estão em risco no país de acolhida e é uma opção viável quando as demais soluções não podem ser efetivadas, como se pode observar no programa implementado na América Latina. Contudo, a solução ainda apresenta desafios a longo prazo.

Palavras-chave: Refugiado. Soluções Duradouras. Reassentamento.

\begin{abstract}
This research deals with the institute of asylum and durable solutions, in particular, the resettlement of refugees. The asylum was institutionalized in the 50s, but, nowadays, there are new factors that generate flows of people outside their countries of origin. Taking into account the non-specific situation of the asylum, durable solutions were created, namely, voluntary repatriation, local integration and resettlement. The solutions are, precisely, a way to continue the life of the refugee, regardless of where they are. Resettlement is the solution that deals with the most vulnerable refugees, as they flee their state and, also, the first host state. In order to analyze the non-punctual situation of the asylum and the role of resettlement, the deductive method is used, using bibliographic and documentary material. Resettlement is an important solution for refugees who are at risk in the host country and is a viable option when other solutions cannot be implemented, as can be seen in the program implemented in Latin America. However, the solution still presents long-term challenges.
\end{abstract}

Keywords: Refugee. Durable Solutions. Resettlement. 


\section{Introdução}

A temática da pesquisa versa sobre o instituto do refúgio e da solução duradoura de reassentamento. O deslocamento é algo natural na história da humanidade, contudo, tem-se, ainda, a discussão acerca das migrações forçadas, ou seja, quando a pessoa não tem poder de escolha e se obriga a abandonar suas origens por conta de fatores externos, como conflitos armados, catástrofes naturais, conflitos internos.

Esses migrantes forçados são englobados pelos fluxos migratórios, assim como os migrantes voluntários, e abarcam a situação dos refugiados. O refúgio foi institucionalizado na década de 1950 e foi criado para uma situação pontual: pessoas que fugiam da Europa durante a Segunda Guerra Mundial. Era pontual, pois se esperava que houvesse uma solução para os problemas e aflições envolvendo as pessoas que forçadamente abandonavam seus lares, fazendo com que a necessidade de existência do instituto chegasse ao fim.

Todavia, o refúgio revela-se como um instituto complexo, dinâmico e paradoxal. Isso porque a situação mostrou-se não pontual, já que há refugiados até os dias de hoje. Observa-se a necessidade de constantes atualizações legislativas ${ }^{1}$, que abarquem novos fatores causadores do refúgio, como, por exemplo, a discriminação com pessoas LGBTI, as pessoas que fogem de desastres naturais e, ainda, os próprios migrantes econômicos, que sofrem, também, por conta de ameaça e violação de direitos. ${ }^{2}$ O próprio mandato do Alto Comissariado das Nações Unidas para Refugiados (ACNUR) possuía prazo final, justamente pela ideia de que, em algum momento, não haveriam mais refugiados a serem tutelados. Contrariamente ao esperado, o mandato do ACNUR tem sido renovado periodicamente na atualidade.

Diante disso, os organismos internacionais envolvidos com a causa migratória passaram a trabalhar com a ideia de soluções duradouras, ou seja, soluções para que os refugiados possam desenvolver suas vidas, já que a ideia inicial de que o instituto iria ter um final, diante do acolhimento de todos os refugiados ou da volta aos seus países de origem, nunca se efetivou. Objetiva-se, assim, com a presente pesquisa, apresentar dados acerca do refúgio, dando enfoque ao trabalho desenvolvimento atualmente pelo ACNUR, e às soluções duradouras, mostrando como essa situação paradoxal que permeia a existência dos refugiados levou à criação dessas soluções.

São três as soluções descritas pelo ACNUR: repatriação voluntária, integração local e reassentamento. A pesquisa introduzirá as três soluções, mas o foco será a solução do reassentamento de refugiados, pois é a que trata da situação dos refugiados mais vulneráveis, pois lida com pessoas que, além de serem perseguidas no país de origem, sofrem violações e ameaças no primeiro país de acolhida. Assim, questiona-se qual a importância da solução do reassentamento para a proteção dos refugiados e para a quebra desse ciclo de

\footnotetext{
${ }^{1}$ A Declaração de Cartagena é um exemplo de ampliação da definição de refugiado e será analisada nesta pesquisa.

${ }^{2}$ Como será observado ao longo desta pesquisa, o refúgio foi institucionalizado pela Convenção de 1951 e o Protocolo de 1967. De acordo com esses dois diplomas, o refugiado é aquela pessoa que está fora do seu país de nacionalidade e não queira/possa retornar e pedir a proteção de seu Estado, em virtude de receio de ser perseguida por razão de raça, religião, nacionalidade, filiação em grupo social ou opiniões políticas. Pessoas LGBTI já são enquadradas em grupo social, mas ainda se tem dificuldades em reconhecer pessoas que fogem de catástrofes naturais, como é o caso dos haitianos, que, no Brasil, são portadores de visto humanitário, não sendo reconhecidos como refugiados. Outro exemplo é a situação dos venezuelanos que, no Brasil, são reconhecidos como refugiados desde 2018. Antes disso, porém, houve muita dificuldade em enquadrar a situação dessas pessoas, pois elas fugiam da crise econômica, política e social da Venezuela, o que não é abarcado pela Convenção de 1951.
} 
violações de direitos humanos. Para exemplificar a utilização da solução do reassentamento, analisa-se o Programa de Reassentamento Solidário, desenvolvido na América Latina, em que o Brasil tem um papel muito importante de incentivador e participante.

Vale ressaltar que não é uma escolha de qual a melhor solução a ser aplicada. Como será estudado, o ideal seria a possibilidade de um trabalho conjunto entre as três soluções, visando a melhor resposta ao refugiado na sua situação concreta. O objetivo deste trabalho é mostrar a importância das soluções duradouras no geral, como uma resposta efetiva ao refúgio, e a importância do reassentamento, em especial, na atualidade, diante do cenário de conflitos regionais constantes e fronteiras fechadas em muitos países. Na prática, como será estudado pelo Programa de Reassentamento Solidário presente na América Latina, há pontos a serem melhorados, o que também justifica a presente discussão.

Utiliza-se o método de abordagem dedutivo, realizando-se a pesquisa a partir do refúgio e das soluções duradouras para chegar ao programa de reassentamento de refugiados na América Latina. O estudo desenvolve-se a partir de material bibliográfico já elaborado, como livros e artigos de periódicos, nacionais e internacionais, e material documental de organizações e agências nacionais e internacionais. O artigo é dividido em quatro capítulos. O primeiro apresenta uma introdução à temática do refúgio. No segundo, analisa-se o surgimento das soluções duradouras. O terceiro capítulo apresenta o foco no reassentamento de refugiados e o quarto capítulo aborda o Programa de Reassentamento Solidário da América Latina.

\section{As origens e paradoxos do refúgio: entre a proteção e o pertencimento}

Ao longo da história da humanidade, o ser humano lidou com a necessidade de, em algum momento, abandonar suas origens por conta de fatores externos. Nesse sentido, Andrade (1996, p. 8) relata que o homem sempre conviveu com o fato de ter que sair de suas origens e buscar proteção em outra localidade, seja por desagradar algum governante ou pela necessidade da terra. A atenção dada a essa questão aumentou no século XX, por conta das duas grandes guerras: enquanto a Primeira Guerra gerou 4 milhões de deslocados, a Segunda gerou mais de 40 milhões. (JUBILUT, 2007, p. 78).

Além do aumento no número de pessoas refugiadas, Jubilut (2007, p. 24-25) expõe um segundo fator que explica a razão pela qual a comunidade internacional passou a se preocupar com a necessidade de criação de normas que protegessem os refugiados somente no século XX: refere-se à organização dos Estados-nações independentes, em que o refugiado sai de sua terra de origem, mas não localiza alternativa para ser acolhido, já que o Estado tem autonomia para não o aceitar em seu território. Ao se dividir o mundo em Estados independentes, divide-se, também, a compreensão de quem é nacional, de dentro, e quem é estrangeiro, de fora, externo, normalmente reconhecido com o outro. Arendt (1998, p. 335-336) menciona que o paradoxo da perda dos direitos humanos é a transformação da pessoa em um humano somente, sem especificações (profissão, cidadania, opinião), perde seu significado por ser individual, singular.

Gera-se, assim, a necessidade de normatizar, perante todos os Estados, o reconhecimento dessas pessoas. Antes da positivação do instituto, a proteção aos refugiados começa a ser pensada durante a Primeira Guerra Mundial (1914-1918), tendo em vista o número extenso de pessoas que saíam da União das Repúblicas 
Socialistas Soviéticas. (JUBILUT, 2007, p. 44). O refúgio, como instituto, surge de duas normas internacionais: a Convenção de 1951 Relativa ao Estatuto dos Refugiados e o Protocolo de 1967 Relativo ao Estatuto dos Refugiados. De acordo com esses dois diplomas, o refugiado é aquela pessoa que está fora do seu país de nacionalidade e não queira/possa retornar e pedir a proteção de seu Estado, em virtude de receio de ser perseguida por razão de raça, religião, nacionalidade, filiação em grupo social ou opiniões políticas. (ORGANIZAÇÃO DAS NAÇÕES UNIDAS, 1951; 1967).

Depois de várias tentativas, em 1949, as Nações Unidas criam o ACNUR, que tem como um dos objetivos buscar soluções duradouras ao refúgio. (GUERRA, 2017, p. 303-304). O ACNUR é um órgão subsidiário da ONU e, da mesma forma que os organismos anteriores, possuí prazo determinado de existência, pois, quando de sua criação, acreditava-se que a situação dos refugiados seria solucionada no pós-guerra, com o retorno das pessoas aos seus lares ou a completa integração em um novo Estado.

Embora tenha se iniciado a institucionalização da proteção aos refugiados, ainda se pensava que era um problema pontual, tanto no tempo quanto no espaço. Por conta disso, os órgãos foram criados com prazo determinado e para situações específicas. (JUBILUT, 2007, p. 25). As decisões e práticas desenvolvidas pelos organismos responsáveis somente supriam inicialmente as necessidades dos refugiados, ao conferir-lhes algum tipo de registro ou permanência, contudo, não integravam realmente essas pessoas a novas localidades ou efetivavam o retorno aos seus lares.

O que se observa, até os dias de hoje, é que o refúgio é dinâmico e constante. Novos conflitos surgem e criam novas situações de refúgio, fazendo com que o mandato do ACNUR tenha que ser periodicamente renovado. $^{3}$ (JUBILUT, 2007, p. 27). Citam-se, como exemplos novos conflitos do século XXI, que geram fluxos de migrantes, a guerra da Síria, iniciada há quase dez anos; a crise econômica, social e política na Venezuela, que leva os venezuelanos aos outros países da América Latina, como, por exemplo, o Brasil; a catástrofe ambiental ocorrida no Haiti, em 2010, dentre outros.

A existências desses novos conflitos comprova que o mundo pós-guerra ainda é palco de fluxos de refugiados. Ainda, evidencia que o refúgio decorre dos fatores dispostos quando da sua institucionalização na década de 1950, mas, também, há novos fatores que não encontram tutela na legislação. É o caso dos refugiados ambientais, que geram diversas discussões no âmbito dos estudos migratórios. Jubilut e Apolinário (2010, p. 288) expõem que, do ponto de vista do direito internacional, expressão refugiado ambiental não está correta, pois a Convenção de 1951 não abrange as pessoas deslocadas por conta de desastres naturais, já que não se visualiza uma situação de perseguição, podendo que o próprio Estado de origem do deslocado ambiental, auxilie as pessoas nessa condição. Contudo, em âmbito regional e até mesmo nacional, pode haver o reconhecimento do refúgio para as pessoas que fogem de desastres naturais, já que alguns Estados podem entender tal situação como perturbação da ordem pública.

\footnotetext{
${ }^{3}$ O ACNUR foi estabelecido pela Assembleia Geral da ONU na Resolução 319 (IV) de 1949 e o Estatuto do ACNUR foi aprovado em 1950 pela Resolução da Assembleia Geral 428 (V). "No âmbito da ONU, a questão dos refugiados, após o estabelecimento do ACNUR, ainda era considerada como sendo de caráter temporário, devendo ser, portanto, resolvida dentro de um marco temporal limitado. O plano inicial era que o ACNUR funcionasse tão-somente durante três anos. Em 1953, contudo, a Assembleia-Geral da ONU decidiu prolongar o mandato ratione temporis do ACNUR a cada cinco anos." (ANDRADE, 2006, lii).
} 
Legislações mais atuais, como, por exemplo, a Declaração de Cartagena, de 1984, adotada na América Latina, apresentam situações mais amplas acerca do refúgio, diante da noção de necessidade de atualização legislativa e observância das realidades regionais. Este instrumento regional não mandatório recomenda a ampliação da definição de refugiado para que se considere, além das previsões universais, a pessoa que tenha fugido do seu país porque sua vida, sua segurança ou sua liberdade tenham sido ameaçadas pela violência generalizada, pela agressão estrangeira, pelos conflitos internos, pela violação maciça dos direitos humanos, ou outras circunstâncias que tenham perturbado gravemente a ordem pública. (JUBILUT; APOLINÁRIO, 2010, p. 283).

Diferentemente dos refugiados do pós-Segunda Guerra, europeus que emigravam para outros continentes, o século XXI apresenta uma migração globalizada, do planeta inteiro, em que países de partida, também são de acolhida e vice-versa. Além de não ser uma situação pontual, a mobilidade mostra-se constante no século XXI, pois seus fatores são estruturais, estando longe de desaparecer: defasagens entre os níveis de desenvolvimento humano, crises políticas e ambientais, falta de esperança nos países pobres. (WENDEN, 2016, p. 18). Esses fatores estão diretamente ligados à violência e ameaça aos direitos humanos.

Assim, diferentemente de uma situação pontual, o refúgio permanece constante na atualidade, pois, segundo dados do ACNUR (2019, p. 2), ao final de 2018, havia 70,8 milhões de pessoas deslocadas forçadamente no mundo, por conta de guerras, conflitos e violência generalizada. Jubilut (2007, p. 205) reconhece que a temática do refúgio é bem desenvolvida, mas ainda extremamente dependente da vontade política do Estado, pois eles efetivam a proteção, por meio de tratados, documentos e leis. Dessa forma, somente se percebe o direito a ter direito e o direito de pertencer a alguma comunidade organizada, quando surgem pessoas que perderam esses direitos e não têm chance de recuperá-los, pois já não há local no mundo a ser civilizado. Isso ocorre porque, paradoxalmente, já são todos parte da mesma humanidade, vivendo em mundo único, em que a perda de direitos significa a expulsão da própria humanidade. (ARENDT, 1998, p. 330).

Os refugiados sempre foram aquelas pessoas fora da humanidade, desprovidos de direitos. Suas vidas são permeadas por paradoxos de pertencimento e não pertencimento. ${ }^{4} \mathrm{O}$ desenvolvimento da proteção dos refugiados, ao longo do século $\mathrm{XX}$, apresentou falhas ao tratar o refúgio como uma situação pontual, não Ihe dando o efetivo amparo. Diante dos contínuos conflitos e das populações de refugiados em busca de novos lares, necessitou-se pensar em soluções que auxiliassem essas pessoas a longo prazo, surgindo, então, a ideia das soluções duradouras.

\section{Soluções duradouras em face da situação não pontual do refúgio}

Neste tópico, serão analisadas a origem e as características das soluções duradouras criadas para a efetivação dos direitos humanos dos refugiados, para, no próximo tópico, atentar-se à solução do reassentamento de refugiados. Andrade (2006, p. cccxi) apresenta que, antes da criação da ONU, já haviam

\footnotetext{
${ }^{4} \mathrm{O}$ que se mostra permanente na vida dos refugiados é o não-pertencimento. Arendt (1998, p. 328) menciona que os refugiados durante a Segunda Guerra Mundial não eram perseguidos por algo que haviam feito ou pensado, mas sim por conta do que simplesmente eram: nascidos na raça errada (judeus na Alemanha), na classe errada (aristocratas na Rússia), convocados pelo governo errado (soldados do Exército Republicano espanhol). As pessoas eram destituídas de direitos humanos justamente por serem somente humanos.
} 
práticas de soluções duradouras para os refugiados, por meio do trabalho da UNRRA (United Nations Relief and Rehabilitation Administration). Na década de 1950, com a criação do ACNUR, muitas mudanças ocorreram no âmbito do direito internacional dos refugiados, dentre elas, a positivação dessas normas por meio da Convenção de 1951 e do Protocolo de 1967.

Como já exposto, o instituto do refúgio foi criado tendo em vista uma situação transitória, contudo, o contrário tem sido a regra e o ACNUR tem seu mandato ampliado por conta de novos moldes que envolvem as migrações forçadas. ${ }^{5}$ (LAFER, 2008, p.322). Para lidar de forma adequada com as situações de refúgio, o ACNUR trabalha com o conceito de situação prolongada que

[...] será o resultado das condições no país de origem dos refugiados, as respostas e condições nos países de acolhimento, a disponibilidade de soluções duradouras e o grau de empenhamento da comunidade internacional, pois algumas situações recebem muito mais atenção do que outras.6 (ACNUR, 2018, p. 22, tradução nossa).

Assim, o ACNUR (2018, p. 22, tradução nossa) entende uma situação de refúgio prolongada quando mais de 25.000 refugiados da mesma nacionalidade permanecem mais de cinco anos no país de destino. Nesse momento, as populações refugiadas já não estão mais na fase de emergência, cuja principal ação é proteção e assistência, mas também não alcançaram uma solução duradoura para seu refúgio. O ACNUR possui um objetivo duplo a ser alcançado: providenciar proteção internacional e buscar soluções permanentes/duradouras para os refugiados, mostrando-se um trabalho humanitário e apolítico. (JUBILUT, 2007, p. 152-153). São três as soluções duradouras apresentadas pelo ACNUR: a repatriação voluntária, a integração local e o reassentamento de refugiados.

Uma solução duradoura é aquela que termina com o ciclo de deslocamento, resolvendo as demandas para que as pessoas possam continuar suas vidas. ${ }^{7}$ (UNHCR, 2011, p. 28, tradução nossa). Não há hierarquia entre as soluções, cada uma teve papel importante em algum momento da história e, ainda, as três soluções, se aplicadas conjuntamente, podem auxiliar de forma completa a resolução da situação de refúgio. ${ }^{8}$ (UNHCR, 2011, p.30, tradução nossa). Mesmo sem hierarquia, a solução duradoura da repatriação voluntária é a prioridade para os próprios refugiados, já que permite o retorno ao país de origem. Deve ser uma decisão livre, com informação e o país de origem deve cooperar com a reintegração da pessoa, para que possa reconstruir sua vida com segurança. Contudo, segundo o relatório do ACNUR, os retornos ocorridos em 2017 foram complexos, por ainda existirem, no país de origem, as ameaças à vida dos refugiados, sem a garantia de reintegração e proteção necessárias. ${ }^{9}$ (ACNUR, 2018, p. 27-28, tradução nossa).

\footnotetext{
${ }^{5}$ Além dos refugiados, o ACNUR tem sob sua proteção, também, os deslocados internos e os apátridas.

6 "Una situación prolongada será el resultado de las condiciones en el país de origen de los refugiados, las respuestas y las condiciones en los países de acogida, la disponibilidad de soluciones duraderas y el grado de compromiso de la comunidad internacional, pues algunas situaciones reciben mucha más atención que otras." (ACNUR, 2018, p. 22).

7 "A durable solution for refugees is one that ends the cycle of displacement by resolving their plight so that they can lead normal lives." (UNHCR, 2011, p. 28).

8 "There is no formal hierarchy among the durable solutions. While in the early years of UNHCR's existence, resettlement and local integration appeared to be the most viable durable solutions for many refugees, over time most refugees have sought and attained voluntary repatriation. The three solutions are complementary in nature and, when applied together, can form a viable and comprehensive strategy for resolving a refugee situation." (UNHCR, 2011, p. 30).

9 "El número de refugiados que regresaron a su país de origen aumentó durante el año hasta alcanzar los 667.400. [...] Aunque el retorno al país de origen suele ser la solución preferida de muchos refugiados, la repatriación debe basarse en una decisión libre e informada y contar con el compromiso
} 
A integração local é uma solução surgida ao final da Segunda Guerra Mundial, quando muitos refugiados não tinham interesse em serem repatriados. (ANDRADE, 2006, p. cxcv). Ela busca um lar permanente no país que acolheu o refugiado. Possui um processo complexo e gradual, pois abarca diversas situações: legais (a nação precisa de uma legislação migratória, que possibilite residência), econômicas (o refugiado precisa ter uma forma de renda), sociais (o refugiado precisa participar da comunidade), culturais. O ideal seria que, com o passar dos anos, o processo de integração local possibilitasse a obtenção da residência permanente ou até mesmo a obtenção da nacionalidade do país de acolhida, o que faria com que a pessoa deixasse de ser refugiada. Os objetivos principais dessa solução duradoura residem na ideia de oferecer meios de desenvolvimento para o refugiado, de forma que ele possa contribuir com o país em que está. ${ }^{10}$ (ACNUR, 2018, p. 30, tradução nossa).

Os primeiros trabalhos no sentido do reassentamento ocorreram em 1946, antes do mandato do ACNUR. Missões da então agência responsável, Comitê intergovernamental para Refugiados (CIR), buscaram nos países sul-americanos contatos para acordos de reassentamento. (ANDRADE, 2006, p. ccviii). O reassentamento é a prática de um Estado acolher refugiados já reconhecidos pelo ACNUR e/ou por outro Estado, mas que não tiveram a proteção necessária nesse primeiro país de acolhida, por vários motivos: necessidade de proteção jurídica e física, necessidade de cuidados médicos específicos, por uma condição especial (como a de crianças e adolescentes, de idosos, de mulheres em situação de risco ou de famílias separadas) ou por total falta de integração local. Resumindo, é o terceiro país do refugiado (contando o seu de origem) e o segundo de acolhida. (JUBILUT, 2007, p. 199).

Para Cançado-Trindade (2003, p. 342), a relação entre a situação dos refugiados e os direitos humanos é que a violação desses direitos é uma das causas principais de ainda existirem refugiados na atualidade. Assim, os direitos humanos deveriam ser respeitados antes do pedido de refúgio, durante esse e depois, na implementação de soluções duradouras. O reassentamento lida com os refugiados mais vulneráveis, pois são pessoas que continuam a sofrer ameaças e violações de direitos humanos no país que os acolhe. É uma ferramenta importante para refugiados que estão em risco no país de acolhida e é uma opção viável quando as demais soluções não podem ser efetivadas. ${ }^{11}$ (UNHCR, 2017, p. 2, tradução nossa). No próximo tópico, serão analisadas as características do reassentamento, diante de sua complexidade de lidar com vidas de refugiados altamente vulneráveis.

total del país de origen con el proceso de reintegración para garantizar que los retornados pueden reconstruir su vida en condiciones de seguridad. Lamentablemente, los contextos en los que se produjeron estos retornos en 2017 fueron a menudo complejos y muchos refugiados regresaron en circunstancias adversas a situaciones en las que no se podía garantizar una reintegración sostenible." (ACNUR, 2018, p. 27-28).

10 "Otra solución duradera para los refugiados es la integración local, que conlleva que el refugiado encuentra un hogar permanente en el país de asilo y se integra en la comunidad local. La integración local es un proceso complejo y gradual que abarca aspectos diferentes pero igualmente importantes: legales, económicos, sociales y culturales. Con el tiempo, el proceso debería culminar con la obtención de derechos de residencia permanente y, en algunos casos, la obtención de la nacionalidad del país de asilo. El objetivo es que los refugiados integrados puedan tener unos medios de vida sostenibles y contribuir a la vida económica del país anfitrión, y vivir entre la población de acogida sin sufrir discriminación ni explotación. Sin embargo, dada su complejidad, resulta difícil medir y cuantificar el grado y la naturaleza de la integración local." (ACNUR, 2018, p. 30).

11 "Resettlement is an important tool of international protection for refugees at risk in the country where they sought asylum, or separated from family members by conflict and flight. Where local integration is not an option, and voluntary repatriation is not viable or feasible in the near future, resettlement may be the only durable solution available, especially in protracted refugee situations." (UNHCR, 2017, p .2). 


\section{Características da solução de reassentamento}

O reassentamento de refugiados é visto, atualmente, pelo ACNUR, como uma das opções mais saudáveis para os refugiados. Diante da configuração internacional, em que há diversos conflitos regionais e fronteiras fechadas, muitas vezes é difícil realizar a repatriação do refugiado, pois esta precisa ser voluntária e muitos refugiados não querem retornar a seus países de origem por medo de ainda sofrerem violações de direitos, ou a integração local, quando as nações, embora deixem os refugiados entrarem em seus territórios, não proporcionam as oportunidades para que tenham direitos básicos, como trabalho, saúde e educação. ${ }^{12}$ (ACNUR, 2018, p. 29, tradução nossa).

O interesse dessa pesquisa em estudar o reassentamento de refugiados reside no fato de o próprio ACNUR reconhecer como a solução mais viável na atualidade, conforme explicado no parágrafo anterior. Ainda, o reassentamento lida com os refugiados mais vulneráveis, pois são pessoas que fogem do Estado que deveria oferecer a acolhida, após a fuga do país de origem. O fato de não poderem retornar aos seus países, não justifica que os refugiados vivam excluídos nas sociedades em que buscam proteção. Nesse sentido, Arendt (1998, p. 331) mostra que "O homem pode perder todos os chamados Direitos do Homem sem perder a sua qualidade essencial de homem, sua dignidade humana. Só a perda da própria comunidade é que o expulsa da humanidade.". A participação, a presença, o fazer parte da comunidade é extremamente importante para os refugiados e o reassentamento é uma ação conjunta de diversos atores para que isso ocorra na prática.

O reassentamento é um processo, desenvolvido pelo trabalho conjunto dos Estados, organizações internacionais e organizações não-governamentais. ${ }^{13}$ (UNHCR, 2011, p. 4, tradução nossa). Divide-se em fases: identificação de refugiados que necessitam ser reassentados; avaliação da necessidade de reassentamento individual; preparação de uma submissão de reassentamento; decisão do país de reassentamento; disposições e acompanhamento prévios à partida. ${ }^{14}$ (UNHCR, 2011, p. 299, tradução nossa).

O ACNUR é responsável por identificar os refugiados que necessitam de reassentamento, contudo, são os Estados que oferecem locais de residência. As organizações governamentais e não-governamentais atuam em todas as fases do processo, principalmente na integração no local de destino. ${ }^{15}$ (UNHCR, 2017, p. 2, tradução nossa). Ainda, o Estado deve arcar com os valores pelo seu programa de reassentamento, que inclui

12 "En 2017, dados el gran número de refugiados y la existencia a menudo limitada de oportunidades para la repatriación voluntaria y la integración local, el reasentamiento siguió desempeñando un papel fundamental como herramienta de protección y solución duradera para algunos de los refugiados más vulnerables del mundo." (ACNUR, 2018, p. 29).

13 "The resettlement of refugees can only be achieved through collaboration with various partners, in particular resettlement States, international organizations and non-governmental organizations (NGOs).” (UNHCR, 2011, p. 4).

14 "The preparation of resettlement submissions must pass through the following common stages of the resettlement process: identification of refugees in need of resettlement consideration; assessment of individual resettlement need; preparation of a resettlement submission; UNHCR submission decision; resettlement country decision; and pre-departure arrangements and monitoring." (UNHCR, 2011, p. 299).

15 "As part of its mandate, UNHCR identifies refugees in need of resettlement, but it is States that offer permanent places of residence in their countries. NGOs and international organizations may also play a key role throughout the identification, pre-departure, and the post-resettlement integration processes." (UNHCR, 2017, p. 2). 
gastos com seleções de missões, consultas médicas, emissão de vistos, viagens. ${ }^{16}$ (UNHCR, 2017, p.12, tradução nossa).

Os Estados que estabeleceram programas regulares de reassentamento de refugiados e concordam em considerar um certo número de submissões do ACNUR a cada ano são considerados Estados de reassentamento. Outros países podem não ter um programa anual, mas também reassentar os refugiados numa base ad hoc e podem manter programas especiais de reassentamento beneficiando os refugiados com necessidades específicas. Os governos têm o papel essencial de estabelecer e manter programas efetivos de reassentamento, incluindo serviços e apoios para ajudar os refugiados reassentados a se integrarem em suas novas comunidades. ${ }^{17}$ (UNHCR, 2017, p. 5, tradução nossa).

As submissões do ACNUR para os programas de reassentamento dos Estados apresentam três níveis de prioridade no atendimento: emergência, urgente e normal. ${ }^{18}$ (UNHCR, 2011, p. 246, tradução nossa). Os casos de emergência precisam ser organizados em até 7 dias; os casos urgentes devem partir em até 6 semanas e os normais devem ser reassentados dentro de 12 meses. ${ }^{19}$ (UNHCR, 2017, p. 10, tradução nossa). O ACNUR tem ciência dos casos que precisam de reassentamento por meio de pesquisas de seus escritórios locais. Essas informações são compiladas anualmente em um documento chamado UNHCR Projected Global Resettlement Needs e divulgadas entre os parceiros no Annual Tripartite Consultations on Resettlement, em Genebra, para que seja discutida a necessidade de cotas de reassentamento, falhas, prioridades, desafios. ${ }^{20}$ (UNHCR, 2017, p. 8, tradução nossa).

O ACNUR seleciona alguns aspectos necessários que os Estados devem possuir para que ofertem vagas de reassentamento, por exemplo, um quadro jurídico e político que ofereça um estatuto legal ao refugiado; estrutura institucional para apoiar o reassentamento, programa de recepção e integração para prestar serviços essenciais, incluindo recepção, orientação, moradia, assistência financeira, assistência médica, aulas

\footnotetext{
16 "Resettlement States are responsible for funding their own resettlement programmes. States are therefore expected to cover the costs including: interview/selection missions, medical checks and pre-departure orientation, exit visas from country of asylum, travel from the country of asylum and on arrival services in the new country of resettlement." (UNHCR, 2017, p. 12).

17 "States that have established regular refugee resettlement programmes and agree to consider a certain number of submissions by UNHCR each year are considered resettlement States. Other countries may not have a yearly programme, but also resettle refugees on an ad hoc basis and may maintain special resettlement programmes benefiting refugees with specific needs. Governments have the essential role of establishing and maintaining effective resettlement programmes, including services and supports to assist resettled refugees to integrate into their new communities." (UNHCR, 2017, p. 5).

18 "UNHCR resettlement submissions have three priority levels: emergency, urgent and normal. This level applies to cases in which the immediacy of security and/or medical condition necessitates removal from the threatening conditions within a few days, if not within hours. [...] Refugees who face conditions requiring their expeditious resettlement, but within a less limited time frame than indicated above, are categorized as urgent cases." (UNHCR, 2011, p. 246).

19 "Emergency cases, which typically involve immediate life-threatening situations, are expected to depart for resettlement within a period not exceeding seven days; urgent cases should depart within six weeks; and normal priority cases are to be resettled within 12 months. These benchmarks are used by UNHCR to gauge whether resettlement activities are efficient and responsive to the protection and resettlement needs of refugees." (UNHCR, 2017, p. 10).

20 "Drawing on these data sources, UNHCR country offices worldwide forecast the refugee resettlement needs for the next calendar year and UNHCR's capacity to address them. This information is compiled in the UNHCR Projected Global Resettlement Needs document, which is then used for planning the global resettlement activities of the Office as it provides the rationale and scope of UNHCR's resettlement operations in any given country. Furthermore, the document allows UNHCR to chart the projected global resettlement needs and its capacity to address those needs; taking into account the resource and other challenges that impact resettlement delivery. This annual UNHCR Projected Global Resettlement Needs document is shared with the resettlement partners in the lead-up to the Annual Tripartite Consultations on Resettlement (ATCR) held in Geneva. The document raises awareness of populations identified as in need of resettlement, and serves as the primary reference document for dialogue on resettlement needs, priorities, likely gaps and challenges in programme delivery, allowing informed decisions on quota and resource allocations. The majority of resettlement States rely on UNHCR to recommend individuals and groups of refugees according to needs and priorities identified by UNHCR and its partners, and to present these individuals for resettlement consideration. The resettlement States assess the individual case submissions made by UNHCR and decide whether or not to grant resettlement according to their policies, laws and regulations." (UNHCR, 2017, p. 8).
} 
de idiomas, preparação para o emprego e educação, e para apoiar o engajamento da comunidade e engajamento público para promover comunidades acolhedoras. ${ }^{21}$ (UNHCR, 2017, p. 5-6, tradução nossa).

Novos Estados na política de reassentamento encontram desafios na integração dos refugiados à nova comunidade, por isso o ACNUR trabalha no sentido de enxergar as necessidades específicas e incentivar programas que se concentrem em um intercâmbio bilateral. ${ }^{22}$ (UNHCR, 2011, p. 69-70, tradução nossa). Jubilut (2007, p. 200) apresenta duas características do reassentamento: primeiro, não é um direito do indivíduo, mas sim uma tentativa de oferecer uma nova oportunidade de integração. Segundo, tem caráter necessariamente voluntário, o refugiado deve concordar em mudar de país de proteção, em atenção ao princípio do nonrefoulement, pois sem a concordância, o refugiado poderia ser devolvido a um país em que sua vida é ameaçada.

Pelo exposto, observa-se que o reassentamento de refugiados é uma alternativa viável em busca de melhores condições para os refugiados, devendo ser um trabalho conjunto entre os Estados, as organizações não-governamentais e o ACNUR. A importância dessa solução para os refugiados reside na possiblidade de um recomeço em suas vidas, mediante toda uma estrutura montada para atender aos seus direitos básicos, como trabalho, educação, moradia, lazer, saúde. Pelo programa de reassentamento, o refugiado é acompanhado, durante um período, por profissionais e pessoas da comunidade que buscam sua participação e seu pertencimento.

Ainda, países que não têm estrutura interna para a acolhida de refugiados permanecem com as fronteiras abertas e acolhem essas pessoas, pois sabem que o reassentamento é um programa que auxilia na realocação dos refugiados para nações preparadas para recebê-los. É, assim, uma forma de compartilhamento de responsabilidades com os países que abrigam a maior parte dos refugiados. ${ }^{23}$ (UNHCR, 2011, p. 4, tradução nossa). Esses resultados, bem como pontos a serem ainda implementados ou aprimorados, podem ser observados na prática de reassentamento desenvolvida na América Latina, por meio do Programa de Reassentamento solidário.

\footnotetext{
21 "A legal and policy framework including legislation to provide resettled refugees a secure legal status on arrival, and access to fundamental civil, political, economic, social and cultural rights, including the prospect of acquiring citizenship; An institutional framework to support resettlement, including decision-making structure, division of responsibilities, and resource allocation, as well as informationsharing and training of key partners including levels of government, nongovernmental organizations, and other service providers; Established processing procedures including quota allocation, case submission, selection and departure procedures; A reception and integration programme to deliver essential services including reception, orientation, housing, financial assistance, medical care, language classes, employment preparation, and education, and to support community engagement; Public engagement to foster welcoming and hospitable communities, including through media attention." (UNHCR, 2017, p. 5-6).

22 "For resettlement to be truly a durable solution, resettled refugees require support to integrate into their new communities. Ensuring that the refugees they resettle integrate effectively remains a major focus for resettlement States, and developing their structural capacity to receive refugees remains a challenge for some of the newer resettlement countries. UNHCR has sought to draw the attention of States to the specific integration needs of resettled refugees, and to encourage integration programmes that focus on a two-way exchange to create welcoming communities and foster positive integration. Negative public attitudes towards persons of concern threaten the protection environment and increase difficulties for UNHCR to secure resettlement places for refugees from certain regions. Racial discrimination and related intolerance are common causes of flight which can also put refugees at risk at subsequent stages of the displacement cycle, including during integration into their new resettlement community." (UNHCR, 2011, p. 69-70).

23 "Resettlement has also brought about positive results that go well beyond those that are usually viewed as a resettlement outcome. In the face of a continued influx of refugees, the use of resettlement has convinced countries of first asylum to keep open their borders, thereby avoiding massive loss of life. In other situations resettlement has played a key role in unlocking the impasses in protracted refugee situations, and opening the possibilities of other durable solutions. Offering resettlement places to refugees in need is also an active expression of responsibility sharing with the countries that host the bulk of the world's refugees. Overall, resettlement is a dynamic and flexible tool, and when done effectively and with strategic vision, the results of resettlement can be powerful beyond the direct impact on the persons resettled." (UNHCR, 2011, p. 4).
} 


\section{Práticas de reassentamento na América Latina}

O reassentamento de refugiados somente se mostra possível diante do trabalho conjunto das nações, do ACNUR e das organizações governamentais e não-governamentais, mostrando ser um mecanismo de compartilhamento de responsabilidades em âmbito internacional, já que auxilia na diminuição dos impactos no primeiro país de refúgio ao propor vagas de reassentamento, que é feito de forma voluntária por cada nação. ${ }^{24}$ (UNHCR, 2017, p. 2, tradução nossa).

Visando o desenvolvimento dessa prática duradoura, os países da América Latina iniciaram o chamado Programa de Reassentamento Solidário. A preocupação com os fluxos migratórios nos países latinoamericanos originou o Colóquio sobre Proteção Internacional dos Refugiados na América Central, México e Panamá, na cidade de Cartagena das Índias, Colômbia. ${ }^{25}$ Desse encontro, surgiu a Declaração de Cartagena, em 1984, instrumento regional não vinculante. A Declaração ampliou a definição de refúgio, tendo sido confirmada em 1994, por ocasião de seu décimo aniversário, quando foi adotada a Declaração de San José sobre Refugiados e Pessoas Deslocadas. (ACNUR, 2015, p. 14).

Em 2004, em comemoração aos 20 anos da Declaração de Cartagena, nações da América Latina e Caribe reuniram-se e aprovaram a Declaração e o Plano de Ação do México (PAM) para Fortalecer a Proteção Internacional dos Refugiados na América Latina. (ACNUR, 2015, p. 13-14). O PAM criou o Programa de Reassentamento Solidário ${ }^{26}$ para fornecer soluções duradouras para refugiados latino-americanos. Inicialmente, foi implementado com colombianos que estavam no Equador e na Costa Rica e foram reassentados na Argentina, no Brasil, no Chile, no Paraguai e no Uruguai. Ainda, 363 refugiados extra regionais se estabeleceram no Brasil, no Chile e no Uruguai. ${ }^{27}$ (UNHCR, 2011, p. 25, tradução nossa). Já no ano de 2014 , no Brasil, foi realizado um encontro para comemorar os 30 anos da Declaração, conhecido como Cartagena+30. No Plano de Ação do Brasil, documento resultante dessa reunião, previu-se a necessidade de abertura do Programa de Reassentamento Solidário a populações de fora da América Latina, principalmente diante da guerra na Síria. ${ }^{28}$ (RUIZ, 2015, p. 25, tradução nossa).

O Programa é organizado em uma estrutura tripartite, dividida entre o ACNUR, os Comitês Nacionais para Refugiados das nações (CONAREs) e organizações da sociedade civil. (MULLER, 2013, p. 236). O ACNUR considera os países latino-americanos de reassentamento emergente, razão pela qual receberam

\footnotetext{
24 "Resettlement is also an international responsibility sharing mechanism, allowing States to offer protection to refugees outside their territories, and reduce problems impacting the country of first asylum. States are not obliged to accept refugees for resettlement, but rather voluntarily offer resettlement places as a tangible expression of international solidarity. Offering resettlement places may also have strategic value, in that providing a durable solution through resettlement for a number of refugees may open avenues for others remaining behind to enjoy improved conditions in the country of asylum. Resettlement can thus be an important element of comprehensive solutions." (UNHCR, 2017, p. 2).

${ }^{25}$ Atualmente, o fluxo migratório mais expressivo na América Latina é de venezuelanos. Diante da crise econômica, social e política pela qual a Venezuela passa, muitas pessoas buscam novas oportunidades nos países fronteiriços, como o Brasil.

${ }^{26}$ Além do Programa de Reassentamento Solidário, o PAM também criou o Programa Cidades Solidárias e o Programa Fronteiras Solidárias.

27 "The Mexico Plan of Action created the Solidarity Resettlement Programme in 2004 to provide durable solutions for Latin American refugees, primarily Colombians in first asylum in Ecuador and Costa Rica, countries that were struggling with large refugee populations. Beginning 2005, 1,151 refugees, mostly Colombians, have been resettled to Argentina, Brazil, Chile, Paraguay, and Uruguay through the SRP. Another 363 extra-regional refugees have resettled in Brazil, Chile, and Uruguay." (UNHCR, 2011, p. 25).

28 "Indeed, the Brazil Plan of Action foresaw such a need and opened the door for solidarity resettlement to extend to extra-regional populations." (RUIZ, 2015, p. 25)
} 
apoio técnico e financeiro do ACNUR e de outros destinos tradicionais de reassentamento, como Noruega e Austrália. (MARCOGLIESE, 2017, p.54). No curto e médio prazo, a questão do financiamento do programa necessitará da convergência de múltiplas fontes, incluindo o ACNUR, os países de reassentamento solidário e a comunidade internacional. Para que haja um futuro para o programa regional de solidariedade, são necessários esforços mais articulados para assegurar recursos para o programa. (WHITE, 2012, p. 81-82).

Desde sua implementação, o programa mostra-se de extrema importância na região, por compartilhar responsabilidades e experiências. Contudo, ainda há alguns desafios, como o da integração dos refugiados à nova comunidade, que deve ser entendida como autossuficiência ao final da assistência financeira ou do período de um ano. (WHITE, 2012, p. 83-84). Para auxiliar nessa demanda, o Estado deve estar envolvido e engajado em todas as etapas do reassentamento, desde o planejamento até a integração, mesmo que a implementação do programa seja de responsabilidade de uma agência parceira da sociedade civil. ${ }^{29}$ (RUIZ, 2015, p. 27, tradução nossa).

Para White (2012, p. 83), uma característica importante de países como Brasil, Chile e Argentina, é o significativo engajamento da sociedade civil. Eles têm numerosas e bem-estabelecidas organizações nãogovernamentais e redes que podem lidar com as necessidades e os desafios que os refugiados enfrentam. A estratégia de diversificação deve incluir parcerias com universidades, que podem oferecer iniciativas criativas de cooperação em várias áreas, desde saúde mental até assistência jurídica.

O Brasil possui um papel fundamental no desenvolvimento do Programa de Reassentamento Solidário na América Latina. Cabe rememorar que o programa surgiu de uma proposta do Brasil e nele foi inicialmente implementado, assim como no Chile e na Argentina, sendo o Brasil e o Chile já precursores no reassentamento antes mesmo da existência do programa. (WHITE, 2012, p. 52). Ao acolher refugiados colombianos e palestinos que se encontravam em situações precárias, por exemplo, no Equador e na Jordânia, o Brasil não reparte o peso apenas com estes países, mas com o próprio sistema de proteção de refugiados, financiado majoritariamente por doações dos países mais ricos para os quais os refugiados seriam normalmente reassentados. Ao assumir a posição de doador de recursos e acolhedor de refugiados reassentados, o Brasil, através do CONARE e seus representantes, assume o compromisso de prestar solidariedade internacional, caracterizando-a também como uma obrigação contratual. (MULLER, 2013, p. 238).

Verifica-se, então, que o reassentamento de refugiados, cada vez mais, é uma alternativa para uma acolhida duradoura dos refugiados. O Programa de Reassentamento Solidário em funcionamento na América Latina apresenta o reconhecimento do outro independente de fronteiras e nacionalidades, a cooperação entre nações como forma de divisão de responsabilidades e a busca de uma tutela de direitos humanos que ultrapasse as fronteiras das nações.

29 "The State must be involved and engaged at every stage of the resettlement process, from planning to integration, even if day-to-day implementation of the programme is in the hands of a partner agency from civil society." (RUIZ, 2015, p. 27). 


\section{Considerações finais}

O presente artigo apresentou a temática das soluções duradouras, em especial, o reassentamento de refugiados e o Programa de Reassentamento Solidário desenvolvido na América Latina como uma forma de acolher e auxiliar a complexa situação pela qual os refugiados passam. A importância do estudo reside no fato de que é crescente o número de pessoas que migram forçadamente, grupo ao qual pertencem os refugiados. Além de uma legislação atualizada para o acolhimento de refugiados, as nações necessitam de políticas migratórias adequadas para que os refugiados façam parte da comunidade e possam desenvolver suas vidas em um novo destino, quando o retorno para o país de origem não se mostra válido.

Ao longo da pesquisa, observou-se que o instituto do refúgio foi criado para ser uma situação pontual, ou seja, esperava-se que, após as medidas tomadas ao término da Segunda Guerra Mundial, as necessidades dos refugiados desaparecessem, estando todos integrados em alguma sociedade ou retornamos aos seus lares. A complexidade e o paradoxo da questão do refúgio residem no fato de que essa situação já se mostrou não pontual. O refúgio não ficou restrito somente ao continente europeu e durante o período da guerra, como disposto, inicialmente, na Convenção de 1951. Atualmente, conflitos no mundo todo geram fluxos de refugiados, governos tiranos, ausência e violação de direitos humanos fazem com que as pessoas busquem uma vida melhor em outros Estados.

Ao verificar que o refúgio era uma situação constante e complexa, o ACNUR voltou-se à implementação das soluções duradouras, já que, em algum momento, teria que lidar com um novo fluxo de refugiados precisando de suporte e tutela. As soluções criadas, a saber, a integração local, a repatriação voluntária e o reassentamento, são possibilidades para que a pessoa em situação de refúgio possa, novamente, ter a oportunidade de fazer parte de uma comunidade, seja retornando ao seu lar (repatriação voluntária), residindo permanentemente em outro local (integração local) ou buscando um novo destino (reassentamento).

O reassentamento foi escolhido como foco do estudo por ser, segundo o ACNUR, a solução mais buscada na atualidade, já que o mundo presencia um crescente número de conflitos regionais (Síria e Venezuela são alguns) que geram novos fluxos de pessoas refugiadas e, por outro lado, presencia uma também crescente mobilização de países desenvolvidos, como, por exemplo, países Europeus e os Estados Unidos da América, em não abrir suas fronteiras ou, abrindo-as, não efetivando os direitos básicos dos refugiados. Assim, não havendo possibilidade de retorno ao seu país de origem ou de integração ao país em que está, os programas de reassentamento conectam países dispostos a receber refugiados com países que os recebem, mas não podem os manter, e com o ACNUR para mediar as conversas.

Assim, sua importância para os refugiados reside no papel fundamental que desempenha em toda a questão migratória, desde o contato com o refugiado para que saia de um ambiente de abusos e violações de direitos, até a realocação dessa pessoa em uma comunidade previamente estudada e preparada para sua acolhida. Como exemplo dessa prática, tem-se o Programa de Reassentamento Solidário desenvolvido na América Latina. O fim desejado pelo Programa de Reassentamento Solidário é o pertencimento do refugiado, para que esse possa se desenvolver pessoal e profissionalmente. O Programa ainda conta com desafios, como o engajamento dos Estados na acolhida dos refugiados e o financiamento das ações, esforços a longo prazo 
para que seja dada continuidade a essa prática importante para as nações da América Latina e para os refugiados que necessitam dela.

\section{Referências}

ACNUR. Global Trends: forced displacement in 2018. Geneva: ACNUR. 2019. Disponível em: https://www.unhcr.org/5d08d7ee7.pdf. Acesso em: 04 jan. 2020.

ACNUR. Memória do trigésimo aniversário da Declaração de Cartagena sobre refugiados. Quito:

ACNUR. 2015. Disponível em: https://www.acnur.org/portugues/wp-

content/uploads/2018/02/Mem\%C3\%B3rias-do-Trig\%C3\%A9simo-Anivers\%C3\%A1rio-da-

Declara\%C3\%A7\%C3\%A3o-de-Cartagena-sobre-refugiados ACNUR2015.pdf. Acesso em: 04 jan. 2020

ANDRADE, José H. Fischel. Direito internacional dos refugiados: evolução histórica (1921-1952). Rio de Janeiro: Renovar, 1996.

ANDRADE, José H. Fischel. A política de proteção a refugiados da organização das Nações Unidas sua gênese no período pós-guerra (1946-1952). 327 f. Tese (Doutorado) - Universidade de Brasília, Instituto de Relações Internacionais, Brasília. 2006.

ARENDT, Hannah. Origens do totalitarismo. Trad. Roberto Raposo. São Paulo: Companhia das Letras, 1998.

CANÇADO-TRINDADE, Antônio Augusto. Tratado de direito internacional dos direitos humanos - v.1. Porto Alegre: Sergio Antonio Fabris, 2003.

FONSECA, Márcio Alves da. Imigração, Estado de Direito e biopolítica. Revista de Filosofia Aurora, v. 28, n. 45, p. 969-984, set./dez, 2016.

GUERRA, Sidney. Direitos humanos: curso elementar. São Paulo: Saraiva, 2017.

JUBILUT, Liliana Lyra; APOLINÁRIO, Silvia Menicucci O. S. A necessidade de proteção internacional no âmbito da migração. Revista Direito GV, v. 6, n. 1, p. 275-294, jan./jun., 2010.

JUBILUT, Liliana Lyra. O direito internacional dos refugiados e sua aplicação no ordenamento jurídico brasileiro. São Paulo: Método, 2007.

LAFER, Celso. Declaração Universal dos Direitos Humanos (1948). In: MAGNOLI, Demétrio (Org.). História da paz. São Paulo: Contexto, 2008, p. 297-329.

MARCOGLIESE, María José. The Solidarity Resettlement Programme, and alternatives, in Latin America.

Forced Migration Review. Oxford, n. 54, February, 2017.

MIGRAÇÃO. In: OIM. Glossário sobre migrações - n. 22. Genebra: OIM, 2009. Disponível em: https://publications.iom.int/system/files/pdf/iml22.pdf. Acesso em: 20 jan. 2020.

MULLER, Paulo Ricardo. Noções de solidariedade e responsabilidade no campo da cooperação internacional para a proteção de refugiados. Revista Internacional de Mobilidade Humana, v. 31, n. 40, p. 229-244, jan./jun., 2013.

ORGANIZAÇÃO DAS NAÇÕES UNIDAS. Convenção Relativa ao Estatuto dos Refugiados - 28 de julho de 1951. 1951. Disponível em:

https://www.acnur.org/fileadmin/Documentos/portugues/BDL/Convencao relativa ao Estatuto dos Refugiad os.pdf. Acesso em: 22 jan. 2020.

ORGANIZAÇÃO DAS NAÇÕES UNIDAS. Protocolo Relativo ao Estatuto dos Refugiados - 4 de outubro de 1967, 1967. Disponível em: 
https://www.acnur.org/fileadmin/Documentos/portugues/BD Legal/Instrumentos Internacionais/Protocolo de 1967.pdf. Acesso em: 22 jan. 2020.

RUIZ, Hiram. Evaluation of Resettlement Programmes in Argentina, Brazil, Chile, Paraguay, and Uruguay. Genebra: UNHCR, 2015.

UNHCR. UNHCR resettlement handbook. Genebra: UNHCR, 2011. Disponível em: https://www.unhcr.org/46f7c0ee2.pdf. Acesso em 22 jan. 2020.

UNHCR. Frequently asked questions about resettlement. Genebra: UNHCR. 2017. Disponível em: https://www.unhcr.org/56fa35b16. Acesso em: 20 jan. 2020.

WHITE, Ana Guglielmelli. Um pilar de proteção (aos refugiados): reassentamento solidário da América Latina. Refúgio, migrações e cidadania, v. 7, n. 7, p. 51-90, 2012. 